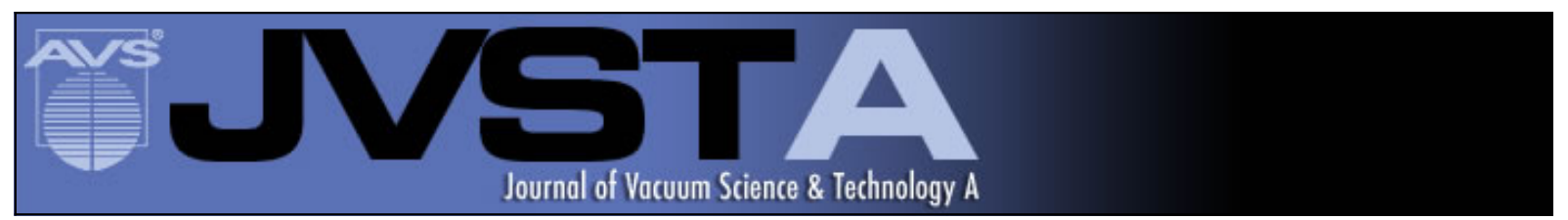

\title{
X-ray reflectivity characterization of atomic layer deposition Al203/TiO2 nanolaminates with ultrathin bilayers
}

Sakari Sintonen, Saima Ali, Oili M. E. Ylivaara, Riikka L. Puurunen, and Harri Lipsanen

Citation: Journal of Vacuum Science \& Technology A 32, 01A111 (2014); doi: 10.1116/1.4833556

View online: http://dx.doi.org/10.1116/1.4833556

View Table of Contents: http://scitation.aip.org/content/avs/journal/jvsta/32/1 ?ver=pdfcov

Published by the AVS: Science \& Technology of Materials, Interfaces, and Processing

\section{Articles you may be interested in}

Low-temperature plasma-enhanced atomic layer deposition of HfO2/Al2O3 nanolaminate structure on $\mathrm{Si}$

J. Vac. Sci. Technol. B 33, 01A101 (2015); 10.1116/1.4895010

Degradation analysis and characterization of multifilamentary conduction patterns in high-field stressed atomic-

layer-deposited TiO2/Al2O3 nanolaminates on GaAs

J. Appl. Phys. 112, 064113 (2012); 10.1063/1.4754510

Giant dielectric constant dominated by Maxwell-Wagner relaxation in Al 2 O 3 / TiO 2 nanolaminates synthesized by atomic layer deposition

Appl. Phys. Lett. 96, 162907 (2010); 10.1063/1.3413961

Electrical characterization of $\mathrm{Al}$ x Ti y O z mixtures and Al $2 \mathrm{O} 3$ - Ti O 2 - Al 2 O 3 nanolaminates

J. Appl. Phys. 102, 114114 (2007); 10.1063/1.2822460

Ultrahigh $\mathrm{x}$-ray reflectivity from $\mathrm{W} / \mathrm{Al} 2 \mathrm{O} 3$ multilayers fabricated using atomic layer deposition

Appl. Phys. Lett. 88, 013116 (2006); 10.1063/1.2161117

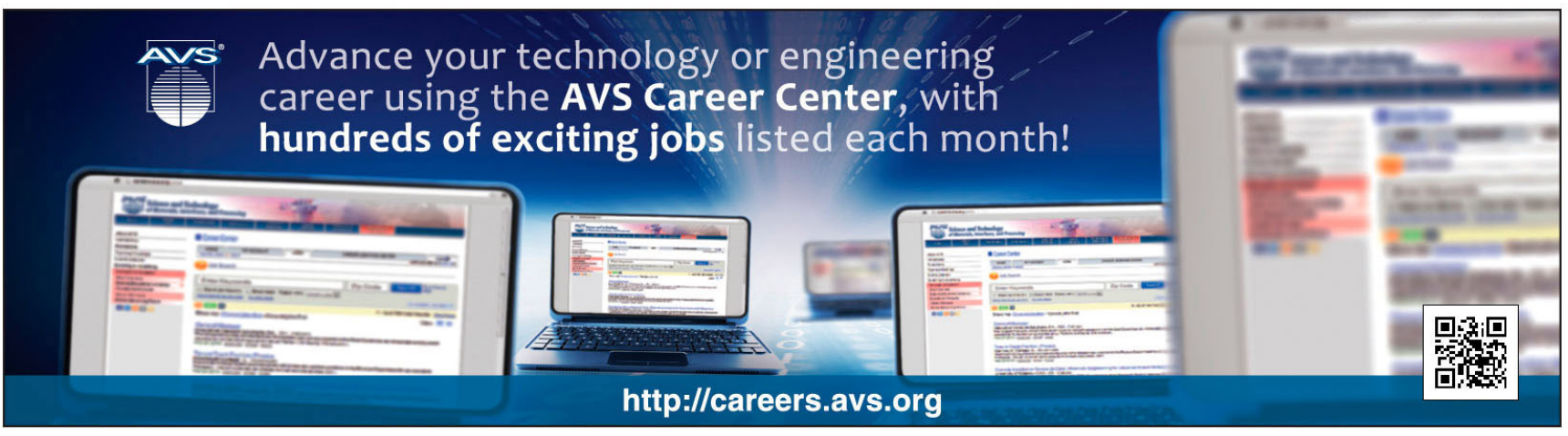




\title{
X-ray reflectivity characterization of atomic layer deposition $\mathrm{Al}_{2} \mathrm{O}_{3} / \mathrm{TiO}_{2}$ nanolaminates with ultrathin bilayers
}

\author{
Sakari Sintonen ${ }^{\text {a) }}$ and Saima Ali \\ Department of Micro- and Nanosciences, Aalto University School of Electrical Engineering, Tietotie 3, \\ 02150 Espoo, Finland \\ Oili M. E. Ylivaara and Riikka L. Puurunen \\ VTT Technical Research Centre of Finland, Tietotie 3, 02150 Espoo, Finland \\ Harri Lipsanen \\ Department of Micro- and Nanosciences, Aalto University School of Electrical Engineering, Tietotie 3, \\ 02150 Espoo, Finland
}

(Received 3 September 2013; accepted 11 November 2013; published 2 December 2013)

\begin{abstract}
Nanolaminate structures have many prospective uses in mechanical, electrical, and optical applications due to the wide selection of materials and precise control over layer thicknesses. In this work, ultrathin $\mathrm{Al}_{2} \mathrm{O}_{3} / \mathrm{TiO}_{2}$ nanolaminate structures deposited by atomic layer deposition from $\mathrm{Me}_{3} \mathrm{Al}, \mathrm{TiCl}_{4}$, and $\mathrm{H}_{2} \mathrm{O}$ precursors with intended bilayer thicknesses ranging from 0.1 to $50 \mathrm{~nm}$ were characterized by x-ray reflectivity (XRR) measurements. The measurements were simulated to obtain values for thickness, density, and roughness of constituting layers. XRR analysis shows that the individual layers within the nanolaminate remain discrete for bilayers as thin as $0.8 \mathrm{~nm}$. Further reduction in bilayer thickness produces a composite of the two materials. (c) 2014 American Vacuum Society. [http://dx.doi.org/10.1116/1.4833556]
\end{abstract}

\section{INTRODUCTION}

Nanolaminates are structures composed of alternating thin layers of different materials. Due to the sequential and self-terminating nature of atomic layer deposition (ALD), alternating films with abrupt interfaces are deposited with excellent control over layer thickness. ${ }^{1,2}$ Additionally, a wide selection of materials can be utilized. ${ }^{3}$ These are beneficial qualities in nanolaminate based mechanical, electrical, and optical applications. ${ }^{2}$

In this work, the structural properties of $\mathrm{Al}_{2} \mathrm{O}_{3} / \mathrm{TiO}_{2}$ nanolaminates were studied by $\mathrm{X}$-ray reflectivity (XRR). $\mathrm{XRR}$ is a powerful and nondestructive technique used to study thin film thickness, density, and roughness. Nanolaminates with varied layer thicknesses were characterized to determine the minimum observable layer thickness. XRR analysis shows that the individual layers within the nanolaminate remain discrete for bilayers as thin as $0.8 \mathrm{~nm}$. Further reduction in bilayer thickness produces a composite of the two materials.

\section{EXPERIMENT}

A series of $\mathrm{Al}_{2} \mathrm{O}_{3} / \mathrm{TiO}_{2}$ nanolaminate samples with varied bilayer thicknesses was studied. In this work, a bilayer denotes the combination of one $\mathrm{Al}_{2} \mathrm{O}_{3}$ and one $\mathrm{TiO}_{2}$ layer. The samples were deposited on 6 in. Si substrates in a Picosun ${ }^{\mathrm{TM}} \mathrm{R}-150 \mathrm{ALD}$ reactor from $\mathrm{Me}_{3} \mathrm{Al}, \mathrm{TiCl}_{4}$, and $\mathrm{H}_{2} \mathrm{O}$ precursors. The deposition temperature was $200^{\circ} \mathrm{C}$ for all samples. A schematic illustration of the nanolaminate structures is seen in Fig. 1. The alternating layer sequence was started with an $\mathrm{Al}_{2} \mathrm{O}_{3}$ layer and an even number of layers were deposited to yield a total nanolaminate thickness of
$100 \mathrm{~nm}$. The nanolaminates were then capped with a $2 \mathrm{~nm}$ $\mathrm{Al}_{2} \mathrm{O}_{3}$ layer. Samples were manufactured with intended bilayer thicknesses from 0.1 to $50 \mathrm{~nm}$. The cycle counts of individual $\mathrm{Al}_{2} \mathrm{O}_{3}$ and $\mathrm{TiO}_{2}$ layers were linearly scaled from known growth rates to approximate equal target thicknesses. Linear scaling was however not possible in the cases of the thinnest films.

The XRR measurements were performed with parallel beam conditions, $\mathrm{x}$-ray wavelength $\mathrm{Cu}-\mathrm{K}_{\alpha}$, acceleration voltage $40 \mathrm{kV}$, and anode current $40 \mathrm{~mA}$. Measured reflectivity curves were simulated using the $\mathrm{X}$ 'pert Reflectivity software to determine the thickness, density, and roughness of the nanolaminate layers. For a review on XRR, see Ref. 4. The reflectivity curves were simulated assuming all bilayers identical, i.e., only one set of thickness, roughness, and density values per material was considered. Since the layers are very thin, both $\mathrm{Al}_{2} \mathrm{O}_{3}$ and $\mathrm{TiO}_{2}$ affect the critical angle of total external reflection and individual densities could not be determined. The $\mathrm{TiO}_{2}$ density was therefore simulated assuming a constant $\mathrm{Al}_{2} \mathrm{O}_{3}$ density $\rho=3.05 \mathrm{~g} / \mathrm{cm}^{3}$. The

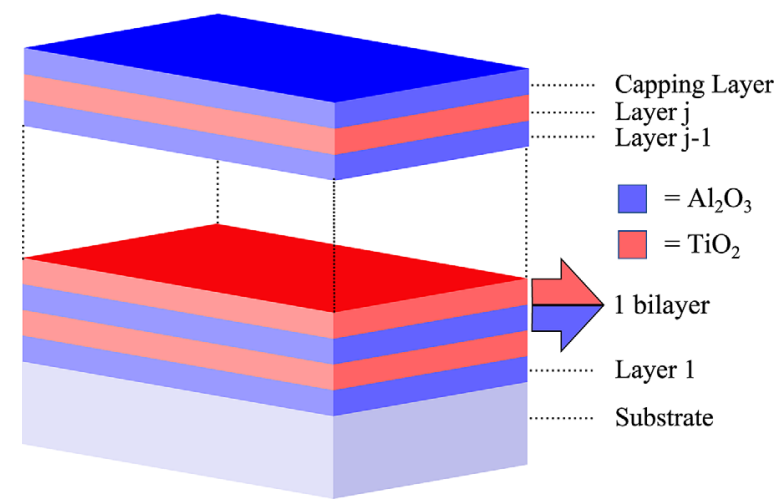
FIG. 1. (Color online) Schematic view of the nanolaminate structure.

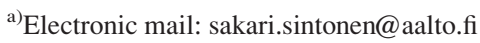




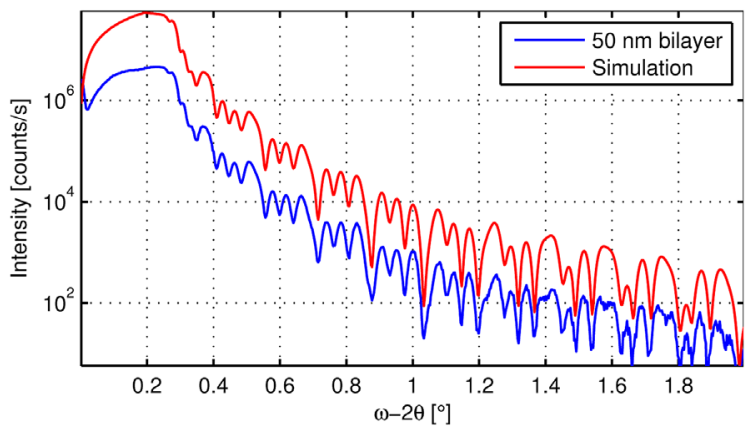

(a)

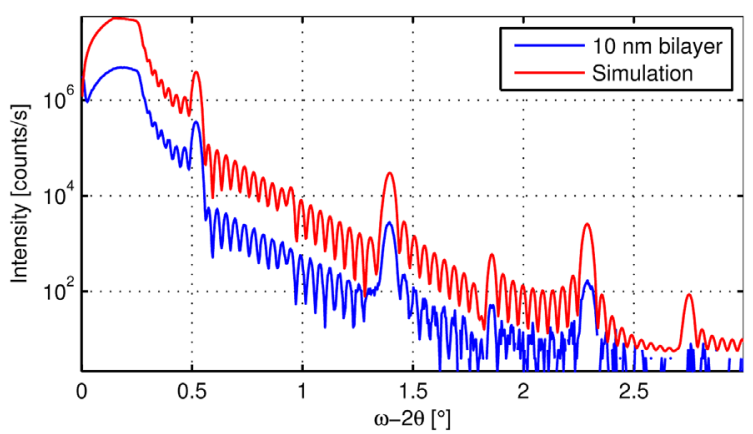

(c)

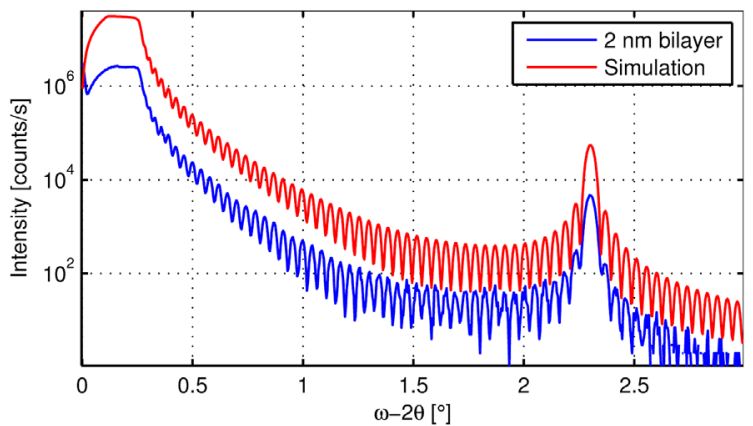

(e)

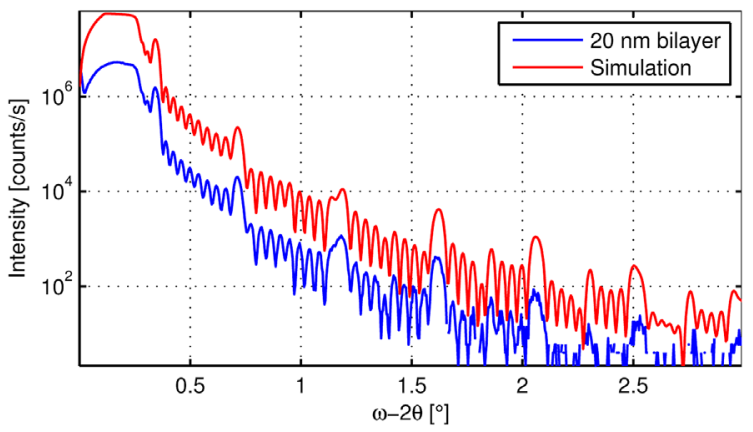

(b)

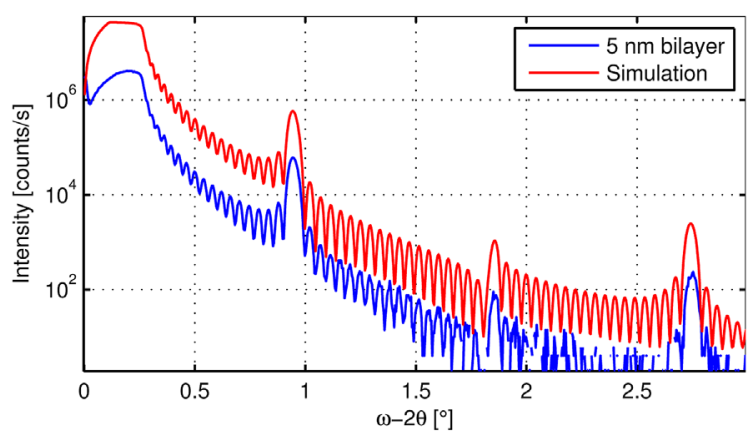

(d)

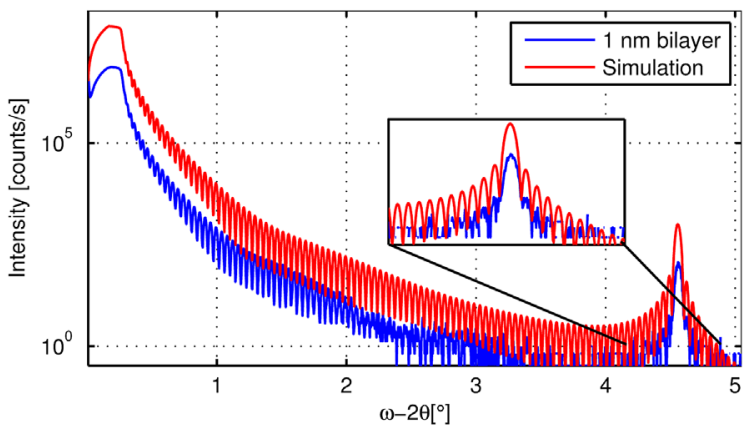

(f)

FIG. 2. (Color online) XRR measurement and simulation curves of samples with target bilayer thicknesses ranging from 1 to $50 \mathrm{~nm}$. Simulation curves are vertically offset for better clarity. The positions of the maxima are related to bilayer thickness and sharpness of the maxima to layer thickness uniformity.

$\mathrm{Al}_{2} \mathrm{O}_{3}$ density value was adopted from experiments of single $\mathrm{Al}_{2} \mathrm{O}_{3}$ films grown at the same temperature ${ }^{5}$ and is in good agreement with earlier published values. 6,7

\section{RESULTS}

Measured and simulated XRR curves of samples with target bilayer thicknesses ranging from 1 to $50 \mathrm{~nm}$ are shown in Fig. 2. The simulations are vertically offset for better clarity. Figure 2 displays how the XRR curves gradually change with decreasing bilayer thickness and increasing bilayer count. The sharp maxima that are first seen in the $20 \mathrm{~nm}$ bilayer sample [Fig. 2(b)] are characteristic of superlattice structures and indicate the bilayers are highly uniform with sharp interfaces. ${ }^{8}$ The shorter oscillation period is inversely proportional to the total nanolaminate thickness. ${ }^{8}$ These shorter oscillations are also in good agreement with the simulations, giving further evidence of layer thickness uniformity.

The period of the superlattice maxima becomes gradually longer as the bilayer thickness decreases. It is seen in Fig. 2(f) that the measurement of the $1 \mathrm{~nm}$ bilayer reaches the noise floor but the maximum corresponding to a repetition of a $\approx 0.5 \mathrm{~nm}$ layer is nevertheless visible at $\approx 4.6^{\circ}$. This suggests that the deposited $\mathrm{Al}_{2} \mathrm{O}_{3}$ and $\mathrm{TiO}_{2}$ layers retain a discrete layer structure even at such a small individual layer thickness.

Additional samples with bilayer thicknesses close to $1 \mathrm{~nm}$ were also studied to confirm the existence of individual $0.5 \mathrm{~nm}$ layers and to determine the point where the layers collapse into a single thick $\mathrm{Ti}_{\mathrm{x}} \mathrm{Al}_{\mathrm{y}} \mathrm{O}_{\mathrm{z}}$ layer. XRR measurements and simulations of samples with intended bilayer thicknesses 1.2, 0.8, and $0.5 \mathrm{~nm}$ are presented in Fig. 3. It can clearly be observed that the $1.2 \mathrm{~nm}$ [Fig. 3(a)] structure demonstrates a superlattice maximum. The corresponding maximum of the $0.8 \mathrm{~nm}$ bilayer [Fig. 3(b)] is barely distinguishable as seen from the enlargement in the inset. The XRR data of the intended $0.5 \mathrm{~nm}$ thick bilayer structure [Fig. 3(c)] lacks the superlattice maximum and only displays the small period oscillation related to total thickness. The measurement curves of samples with even smaller intended thicknesses were similar to Fig. 3(c) and are not shown here. 


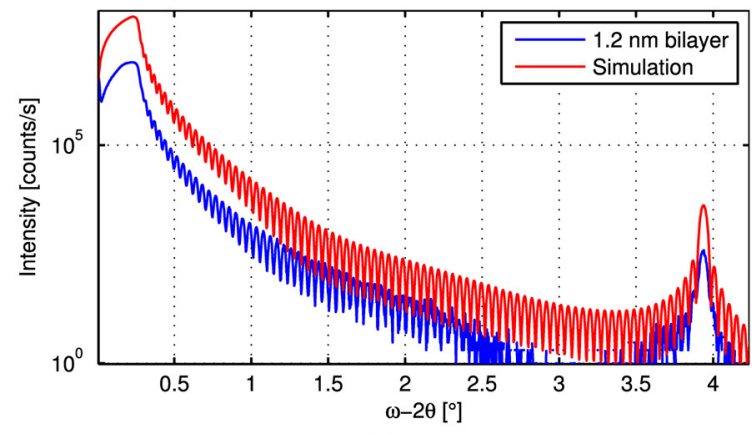

(a)

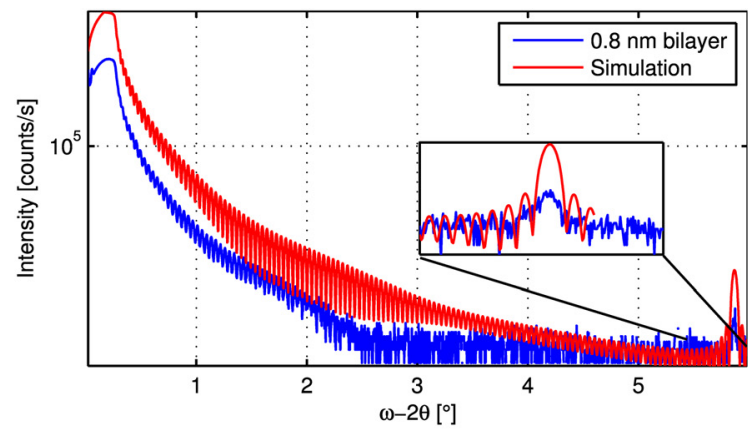

(b)

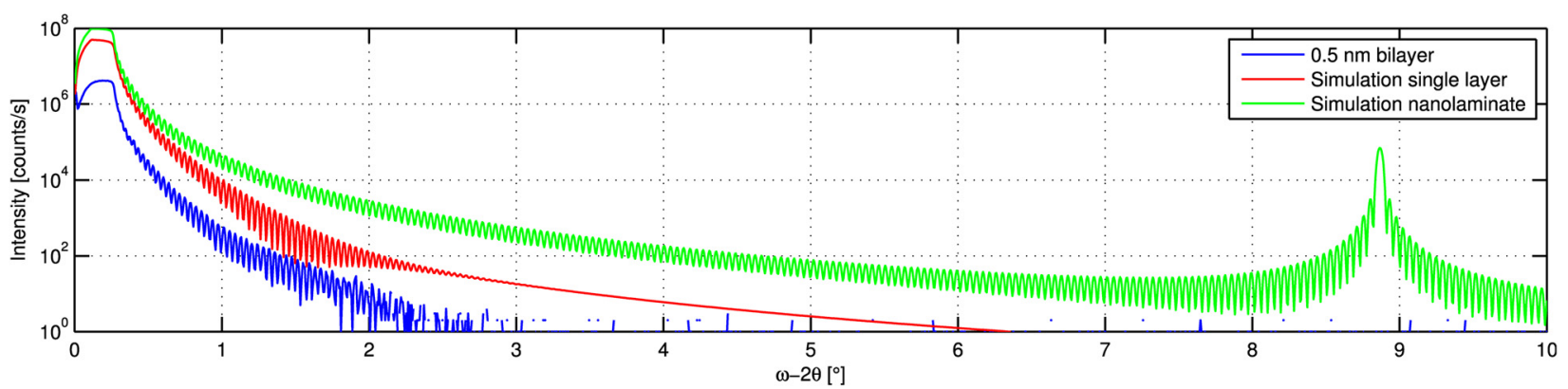

(c)

FIG. 3. (Color online) XRR measurement and simulation curves of samples with target bilayer thicknesses ranging from 1.2 to 0.5 nm. Simulation curves are vertically offset for better clarity. The positions of the maxima are related to bilayer thickness and sharpness of the maxima to layer thickness uniformity.

XRR measurements therefore indicate the studied $\mathrm{Al}_{2} \mathrm{O}_{3} / \mathrm{TiO}_{2}$ nanolaminates maintain a layered structure down to $\approx 0.4 \mathrm{~nm}$ individual layer thickness. These results are in good agreement with a similar study on $\mathrm{ZnO} / \mathrm{Al}_{2} \mathrm{O}_{3}$ nanolaminates, where the observed minimum bilayer thickness was $1.6 \mathrm{~nm} .{ }^{9}$ In the case of $\mathrm{ZnO} / \mathrm{Al}_{2} \mathrm{O}_{3}$, no layering was observed for bilayer thickness $0.8 \mathrm{~nm}$, but the multilayer signal could have been obscured by interfacial roughness or thickness variations.

The growth cycle numbers and results based on simulations of XRR measurements are summarized in Table I, where $\mathrm{t}_{\mathrm{BL}}$ denotes bilayer thickness, $\rho$ mass density, and $\sigma$ interface roughness. The $\mathrm{TiO}_{2}$ content has been calculated as the thickness weighted average of the $\mathrm{TiO}_{2}$ density. The simulated thicknesses are in good agreement with target thicknesses, although the simulated values are systematically $\approx 3 \%$ smaller than the target values. This is a rather small discrepancy and is a consequence of linearly scaling cycle numbers from values used for thicker films with uncertainty in the thickness value. The accuracy of thin film thickness is generally not limited by the instrument resolution but the accuracy of simulation. ${ }^{10}$ The accuracy is therefore case dependent and reported values for a single or bilayer are in the range of \pm 0.2 to $0.5 \mathrm{~nm}$ (Refs. 11 and 12) and \pm 0.1 for a multilayer. ${ }^{10}$ However, due to repetition of the bilayer the position of a superlattice maximum is extremely sensitive to

TABLE I. ALD cycle numbers for individual layers and a summary of the XRR results for samples with intended bilayer thickness ranging from 0.1 to $50 \mathrm{~nm}$. The $\mathrm{TiO}_{2}$ content has been calculated as the thickness weighted average of the $\mathrm{TiO}_{2}$ density.

\begin{tabular}{|c|c|c|c|c|c|c|c|c|c|c|c|}
\hline \multirow{3}{*}{$\frac{\text { Target } t_{B L}(\mathrm{~nm})}{0.10}$} & \multirow{2}{*}{\multicolumn{2}{|c|}{$\begin{array}{l}\text { Cycles/layer } \\
\mathrm{Al}_{2} \mathrm{O}_{3} \mathrm{TiO}_{2}\end{array}$}} & \multirow{3}{*}{$\frac{\text { Cycle ratio } \mathrm{TiO}_{2} / \mathrm{Al}_{2} \mathrm{O}_{3}}{1}$} & \multirow{3}{*}{$\frac{\text { Measured } t_{B L}(\mathrm{~nm})}{\text { Single layer }}$} & \multirow{2}{*}{\multicolumn{2}{|c|}{$\begin{array}{c}t(\mathrm{~nm}) \\
\mathrm{Al}_{2} \mathrm{O}_{3} \mathrm{TiO}_{2}\end{array}$}} & \multirow{2}{*}{\multicolumn{2}{|c|}{$\begin{array}{c}\rho\left(\mathrm{g} / \mathrm{cm}^{3}\right) \\
\mathrm{Al}_{2} \mathrm{O}_{3} \mathrm{TiO}_{2}\end{array}$}} & \multirow{2}{*}{\multicolumn{2}{|c|}{$\begin{array}{c}\sigma(\mathrm{nm}) \\
\mathrm{Al}_{2} \mathrm{O}_{3} \mathrm{TiO}_{2}\end{array}$}} & \multirow{3}{*}{$\mathrm{TiO}_{2}$ content $(\%)$} \\
\hline & & & & & & & & & & & \\
\hline & 1 & 1 & & & \multicolumn{2}{|c|}{138.5} & \multicolumn{2}{|c|}{3.35} & \multicolumn{2}{|c|}{0.9} & \\
\hline 0.25 & 1 & 3 & 3 & Single layer & \multicolumn{2}{|c|}{94.0} & \multicolumn{2}{|c|}{3.70} & \multicolumn{2}{|c|}{0.9} & \\
\hline 0.50 & 3 & 6 & 2 & Single layer & \multicolumn{2}{|c|}{110.5} & & & \multicolumn{2}{|c|}{0.8} & \\
\hline 0.80 & 4 & 9 & 2.5 & 0.76 & 0.38 & 0.38 & 3.05 & 3.90 & 0.3 & 0.3 & 56 \\
\hline 1.00 & 5 & 12 & 2.4 & 0.97 & 0.49 & 0.48 & 3.05 & 4.00 & 0.4 & 0.3 & 56 \\
\hline 1.20 & 6 & 15 & 2.5 & 1.12 & 0.56 & 0.56 & 3.05 & 3.90 & 0.4 & 0.3 & 56 \\
\hline 2.00 & 10 & 25 & 2.5 & 1.93 & 1.00 & 0.93 & 3.05 & 3.70 & 0.2 & 0.2 & 53 \\
\hline 5.00 & 26 & 62 & 2.4 & 4.85 & 2.30 & 2.55 & 3.05 & 3.75 & 0.3 & 0.3 & 58 \\
\hline 10.0 & 52 & 123 & 2.4 & 9.70 & 4.70 & 5.00 & 3.05 & 3.75 & 0.3 & 0.3 & 57 \\
\hline 20.0 & 104 & 247 & 2.4 & 19.40 & 9.50 & 9.90 & 3.05 & 3.75 & 0.3 & 0.3 & 56 \\
\hline 50.0 & 259 & 617 & 2.4 & 48.20 & 23.70 & 24.50 & 3.05 & 3.80 & 0.3 & 0.3 & 56 \\
\hline
\end{tabular}


the bilayer thickness and a change of $0.1 \mathrm{~nm}$ in a simulation is clearly observed. While the position of the superlattice maximum corresponds to the bilayer thickness, individual layer thicknesses are determined with fair precision by fitting the relative intensities of the superlattice maxima. As an example, in Fig. 2(c), the even number maxima have lower intensities, and this data may be used to fit individual thicknesses, as predicted by Parratt. ${ }^{13}$ Samples for which only one superlattice maximum could be recorded, i.e., bilayer thicknesses $\leq 2 \mathrm{~nm}$, thus have greater uncertainty in the simulated individual thicknesses. These simulations were carried out assuming equal or close to equal layer thicknesses.

Interestingly, the smallest observed bilayer thickness before layer disintegration was $0.76 \mathrm{~nm}$, simulated with equal $0.38 \mathrm{~nm}$ layer thicknesses. This is probably close to the achievable minimum thickness, since one estimate for $\mathrm{Al}_{2} \mathrm{O}_{3}$ monolayer thickness with density $3.05 \mathrm{~g} / \mathrm{cm}^{3}$ is 0.38 $\mathrm{nm} .{ }^{2,14}$ Using the same method of calculation as in Refs. 2 and 14 , the estimated $\mathrm{TiO}_{2}$ monolayer thickness is $0.33 \mathrm{~nm}$, assuming a $\mathrm{TiO}_{2}$ density of $3.75 \mathrm{~g} / \mathrm{cm}^{3}$.

The practically constant roughness values presented in Table I support the conclusion that interfaces are on average very sharp. The small roughness values also indicate that the $\mathrm{TiO}_{2}$ films are amorphous, since crystalline films are known to have rough surfaces due to columnar growth. ${ }^{15}$ Since the deposition temperature was above the crystallization temperature of the $\mathrm{TiO}_{2}$ anatase phase, powder x-ray diffraction (XRD), and grazing incidence XRD measurements were performed to investigate the crystallinity of the samples. No evidence of crystallinity was found for either material. $\mathrm{TiO}_{2}$ anatase phase has previously been detected with the same XRD setup in $15 \mathrm{~nm}$ thick films and the lack of diffraction signal cannot therefore be explained by a small diffracting volume.

The simulated density values are within the measurement accuracy $\left( \pm 0.05 \text { to } 0.1 \mathrm{~g} / \mathrm{cm}^{3}\right)^{11,16}$ also constant down to $2 \mathrm{~nm}$ bilayer thickness. The XRR results of bilayers thinner than $2 \mathrm{~nm}$ suggest a higher average density, indicating an increased $\mathrm{Ti}$ incorporation. The elevated density values have not been validated with alternative measurements. Since $\mathrm{XRR}$ is an averaging technique, the measured density of very thin layers is an average density, influenced by the densities and thicknesses of both constituting materials. It is therefore likely that the $\mathrm{TiO}_{2}$ layers are thicker than the $\mathrm{Al}_{2} \mathrm{O}_{3}$ layers in samples with bilayer thickness greater than $2 \mathrm{~nm}$. The individual thicknesses of bilayers $\leq 2 \mathrm{~nm}$ could not be accurately fitted due to lack of multiple superlattice maxima and were fitted assuming equal or close to equal layer thicknesses. The practically constant $\mathrm{TiO}_{2}$ content shown in Table I favors the greater $\mathrm{TiO}_{2}$ thickness over elevated density.
Table I shows that the densities and film thicknesses vary greatly in the samples with decomposed $\mathrm{Ti}_{x} \mathrm{Al}_{y} \mathrm{O}_{z}$ layers. The density values are a result of the change in $\mathrm{TiO}_{2} / \mathrm{Al}_{2} \mathrm{O}_{3}$ cycle ratios due to small cycle numbers. The thickness is in good agreement with the total number of cycles, not displayed in Table I.

\section{CONCLUSIONS}

$\mathrm{Al}_{2} \mathrm{O}_{3} / \mathrm{TiO}_{2}$ nanolaminates with varied bilayer thicknesses were studied by $\mathrm{x}$-ray reflectivity. Film thickness, density, and roughness values were determined by simulating XRR curves of nanolaminate structures with target bilayer thicknesses ranging from 0.1 to $50 \mathrm{~nm}$. The nanolaminates were found to preserve an alternating layer structure down to individual layer thickness of $0.38 \mathrm{~nm}$ after which the nanolaminates decompose into single $\mathrm{Ti}_{\mathrm{x}} \mathrm{Al}_{\mathrm{y}} \mathrm{O}_{\mathrm{z}}$ layers. XRR measurements show that the layers are uniform with sharp interfaces. It was shown that XRR is a viable technique for structural characterization of nanolaminates with ultrathin layers.

\section{ACKNOWLEDGMENTS}

This work has been carried out within the MECHALD project funded by Tekes and is linked to the Finnish Centers of Excellence in Atomic Layer Deposition (ref. 251220) of the Academy of Finland. Sintonen is grateful to Svenska Kulturfonden for financial support.

${ }^{1}$ R. L. Puurunen, J. Appl. Phys. 97, 121301 (2005).

${ }^{2}$ S. George, Chem. Rev. 110, 111 (2010).

${ }^{3}$ V. Miikkulainen, M. Leskela, M. Ritala, and R. L. Puurunen, J. Appl. Phys. 113, 021301 (2013).

${ }^{4}$ K. Stoev and K. Sakurai, Spectrochim. Acta, Part B 54, 41 (1999).

${ }^{5}$ O. M. E. Ylivaara et al., "Aluminum oxide from trimethyla-luminum and water by atomic layer deposition: residual stress, elastic modulus, hardness and adhesion," Thin Solid Films (to be published).

${ }^{6}$ M. D. Groner, F. H. Fabreguette, J. W. Elam, and S. M. George, Chem. Mater. 16, 639 (2004).

${ }^{7}$ G. Dingemans, M. Van de Sanden, and W. Kessels, Electrochem. Solid State Lett. 13, H76 (2010).

${ }^{8}$ M. Moram and M. Vickers, Rep. Prog. Phys. 72, 036502 (2009).

${ }^{9}$ J. M. Jensen, A. B. Oelkers, R. Toivola, D. C. Johnson, J. W. Elam, and S. M. George, Chem. Mater. 14, 2276 (2002).

${ }^{10}$ P. Colombi et al., J. Appl. Crystallogr. 41, 143 (2008).

${ }^{11}$ R. E. Sah, R. Driad, F. Bernhardt, L. Kirste, C.-C. Leancu, H. Czap, F. Benkhelifa, M. Mikulla, and O. Ambacher, J. Vac. Sci. Technol. A 31, 041502 (2013).

${ }^{12}$ R. Matyi et al., Thin Solid Films 516, 7962 (2008) ["Current trends in optical and x-ray metrology of advanced materials and devices $\{$ II $\}$," in Proceedings of the EMRS 2007 Fall Meeting Symposium H, Warsaw, Poland].

${ }^{13}$ L. G. Parratt, Phys. Rev. 95, 359 (1954).

${ }^{14}$ R. L. Puurunen, Chem. Vap. Depos. 9, 249 (2003).

${ }^{15}$ J. Aarik, A. Aidla, T. Uustare, and V. Sammelselg, J. Cryst. Growth 148, 268 (1995).

${ }^{16}$ A. Ferrari, B. Kleinsorge, G. Adamopoulos, J. Robertson, W. Milne, V. Stolojan, L. Brown, A. LiBassi, and B. Tanner, J. Non-Cryst. Solids 266-269, 765 (2000). 